\title{
Application of the fuzzy analytic hierarchy process in multi-criteria decision in Noise Action Plans: prioritizing road stretches
}

\author{
Alejandro Ruiz-Padillo ${ }^{\mathrm{a}}$, Antonio J. Torija ${ }^{\mathrm{b}}$, Ramos-Ridao A.F., Diego P. Ruiz ${ }^{\mathrm{c}}$
}

a Civil Engineering Department, Escuela Técnica Superior de Ingenieros de Caminos, Canales y Puertos, University of Granada. Edificio Politécnico, Campus Fuentenueva s/n, 18071 Granada, Spain.

${ }^{\mathrm{b}}$ ISVR, University of Southampton, Highfield Campus, SO17 1BJ Southampton, UK.

${ }^{\mathrm{c}}$ Information Technology and Communication Research Center (CITIC-UGR), Applied Physics Department, Faculty of Sciences, University of Granada, Spain.

Tel: +34 958244161

Fax: +34 958243214

E-mail: aruizp@correo.ugr.es, aleruizpadillo@hotmail.com (Alejandro Ruiz-Padillo); ajtorija@ugr.es (Antonio J. Torija); druiz@ugr.es (Diego P. Ruiz); ramosr@ugr.es (Ángel F. Ramos-Ridao)

\section{Abstract}

Traffic noise is one of the major environmental impacts of road infrastructures. Critical study of published Noise Action Plans (NAP) signals a widespread lack of objective criteria and methodologies for prioritizing actions against noise as well as the suitability of solutions. The present paper develops a methodology to sort, by priority, road stretches included in a NAP. In obtaining and allocating weights to variables involved in the decision-making problem ("Road Stretch Priority Variables”) to define a normalized numerical index (“Road Stretch Priority Index”), Fuzzy Analytic Hierarchy Process (FAHP) with two different defuzzification methods is applied to the results of an expert panel. Comparison of the outcomes of both FAHP versions, plus analysis of the results of a case study, enables to determine the relative influence of these variables in the problem. An objective and reasoned methodology for the prioritized classification of road stretches according to noise problems is thereby validated. 
Keywords: road traffic noise; strategic noise maps; road noise action plans; multicriteria decision-making; road stretch variables; fuzzy analytic hierarchy process. 


\section{Introduction.}

The road traffic noise exposure problem has intensified in recent years, and stands out over the other environmental and urban noise sources, such us industry, aircraft, railway, or leisure activities. In Europe, initiatives and current legislation respond by providing tools for local Administrations and society as a whole in order to combat this serious adverse effect of road infrastructure on the environment and the health of inhabitants (De Vos, 2009; WHO, 2011; EEA, 2014).

The main objectives of the European Parliament and of The Council of 25 June 2002, on the assessment and management of environmental noise (or "European Environmental Noise Directive”) (European Union, 2002) included the evaluation of this problem in the biggest European road infrastructures, assessing the number of exposed people, and mapping sound levels using simulation software and specific noise indicators (De Vos, 2008; Licitra and Ascari, 2014).

The problem appears to be getting out of hand in several European countries. This negative trend can be seen through the data of road traffic noise exposure reflected in the Strategic Noise Maps (SNM) generated in application of the Environmental Noise Directive, and the design and implementation of numerous measures against road traffic noise. The Public Administrations involved have furthermore approved and adopted several measures in their plans for action against noise (EEA, 2014; Mileu et al., 2010). The Noise Action Plans (NAP) published in Spain up to date (available at sicaweb.cedex.es) were analyzed, and a critical review of them served us to confirm a widespread lack of prioritization criteria for pertinent actions, both at the level of management of stretches and suitability of solutions. Moreover, all these NAPs dealt with a narrow spectrum of possible alternatives.

Decision-making concerning the actions included in these NAP as a result of the SNM must take into account several variables and criteria, such us traffic data, noise levels and exposure values, the environment characteristics and local constraints (WGAEN, 2007; Silence project, 2009; De Vos, 2008). These elements are often in conflict and not clearly defined, and may have an impact of diverse intensity or nature (Torija et al., 2010; D’Alessandro and Schiavoni, 2015; Licitra et al., 2011). Moreover, the different methods employed by the Member States in the noise simulation and the estimation of 
the noise exposure values imply that the reported data are not directly comparable, and action plans may be heavily dependent on these issues (Licitra et al., 2012; D’Alessandro and Schiavoni, 2015). Therefore, in the current engineering panorama, planning processes are highly complex due to such associated uncertainties and their eventual significance (De Vos, 2009; Brown and Elms, 2015).

Moreover, many Member States and researchers have developed different approaches to determine the priority for action against noise among the so-called "hotspots" considering various criteria and procedures (De Vos, 2008; Licitra et al., 2011). Some of these experiences define single or aggregated indicators, that are very useful to technicians and policy makers to understand and express reasoned decisions and comparisons in a more comprehensive way (Licitra and Ascari, 2014; D’Alessandro and Schiavoni, 2015). However, a considerable controversy still exists concerning which the most important principles must be in the noise action planning (De Vos, 2009).

A previous paper (Ruiz-Padillo et al., 2014) presented a preliminary methodology to sort, by priority, road stretches included in a particular NAP. Based on the so-called "road stretch priority index" (RSPI), the method combines the weighted influence of several "road stretch priority variables" (RSPV) through a few weights and intervals defined for this purpose, obtained from the RSPV bibliographic review and in the light of the results of Naish (2010). But there is a need to determine them in a more objective way. The value allocation system using intervals might also be improved to avoid sensitivity problems in the methodology.

Therefore, the present study proposes a methodology for weight allocation for these RSPV by applying the analytic hierarchy process in its fuzzy version (FAHP) to the results obtained from ad hoc questionnaires prepared for an expert panel. Discussion of the obtained results features a qualitative comparison between the different FAHP versions used to sort and weigh variables. Testing the adaptability of the developed methodology to real cases entailed a practical application involving the reviewed Noise Action Plan for regional roads of the province of Almería, in Andalusia (southern Spain). The proposed methodology can use input data from the SNM, regardless of the method employed to simulate and estimate the road traffic noise. The obtained weights are independent of the origin of the data used for the variable calculation, as presented in section 3.1. 


\section{Material and Methods.}

\subsection{RSPV and RSPI.}

The main RSPV were determined and defined in Ruiz-Padillo et al. (2014), while the present paper introduces the following improvements:

- Stretch traffic data: in addition to the intensity of vehicles (average daily traffic - $A D T)$ and the percentage of heavy vehicles (\%hv), the average speed of the vehicles in the stretch (s) is added, since it also bears influence on the generation and reduction of noise, as evidenced in the noise mapping (Naish, 2010, Ouis, 2001).

- Complaints about traffic noise produced in a particular road stretch, if existing, would be covered in the variable $E_{C}$ (taking on a binary value, either "yes" or "no", which translates into respective numerical values of 1 and 0 ).

- The RSPV noise level of necessary attenuation $(\Delta L)$ is divided into two subvariables, depending on the time-slot; this is because sound levels during day- or nighttime periods should not be given the same emphasis. A community noise annoyance degree is higher during the night, even at lower sound levels. Thus, two sub-variables are considered: the minimum attenuation in the daytime period, $\Delta L_{d}$, and the minimum attenuation at night, $\Delta L_{n}$. Then, taking into account the definition of noise indicators (European Union, 2002; D’Alessandro and Schiavoni, 2015) offered by the SNM, noise levels of necessary attenuations are calculated by Eq. 1 and 2:

$$
\begin{aligned}
& \Delta L_{d}=L_{e x i s t, d}-L_{o b j, d} \\
& \Delta L_{n}=L_{e x i s t, n}-L_{o b j, n}
\end{aligned}
$$

where $\Delta L_{d}$ is the daytime necessary attenuation in $\mathrm{dB}(\mathrm{A})$;

$L_{e x i s t, d}$ is the A-weighted long-term average sound level determined over all the day and evening periods of a year (i.e. it includes the daytime period, 7:00 to 19:00, and the evening period, 19:00 to 23:00), obtained from the noise map;

$L_{o b j, d}$ is the A-weighted sound level corresponding to acoustic quality objectives for day and evening periods, in view of the corresponding noise zoning of the stretch studied under current legislation; 
$\Delta L_{n}$ is the night-time required attenuation in $\mathrm{dB}(\mathrm{A})$;

$L_{\text {exist, } n}$ is the A-weighted long-term average sound level determined over all the night periods of a year (23:00 to 7:00), obtained from the noise map; and

$L_{o b j, n}$ is the A-weighted sound level corresponding to the night-time acoustic quality objective, in view of the corresponding noise zoning of the stretch studied under current legislation.

- Exposed surface $\left(S_{\text {exp }}\right)$ and exposed population $\left(P_{\text {exp }}\right)$ to excessive noise level (i.e. sound levels above legislation limits) are also extracted from the SNM, relative to values of the $L_{d e n}$, day-evening-night noise indicator, defined by Eq. 3 (European Union, 2002):

$$
L_{\text {den }}=10 \log \left(\frac{12 \cdot 10^{\frac{L_{\text {day }}}{10}}+4 \cdot 10^{\frac{L_{\text {evening }}+5}{10}}+8 \cdot 10^{\frac{L_{\text {night }}+10}{10}}}{24}\right)
$$

in which $L_{d a y}$ is the $A$-weighted long-term average sound level determined over all the day periods of a year (7:00 to 19:00);

$L_{\text {evening }}$ is the $A$-weighted long-term average sound level determined over all the evening periods of a year (19:00 to 23:00); and

$L_{\text {night }}$ is the $A$-weighted long-term average sound level determined over all the night periods of a year (23:00 to 7:00).

In the SNM these data are distributed by intervals of sound levels, which are usually the following: from 55 to $65 \mathrm{~dB}(\mathrm{~A})$, from 65 to $75 \mathrm{~dB}(\mathrm{~A})$, and values higher than $75 \mathrm{~dB}(\mathrm{~A})$ (European Union, 2002; D’Alessandro and Schiavoni, 2015). In fact, it is reasonable to assume that equal importance should not be given to a surface or people exposed to sound levels close to acoustic quality objective levels as opposed to those who are affected by much higher local sound levels. Therefore, based on the information of $L_{d e n}$ distributed by intervals obtained from the noise maps, both $S_{\exp }$ and $P_{\exp }$ variables can be subdivided into three sub-variables according to these intervals, i.e. surface and population exposed to sound levels between 55 and $65 \mathrm{~dB}(\mathrm{~A})$, between 65 and $75 \mathrm{~dB}(\mathrm{~A})$, and higher than $75 \mathrm{~dB}(\mathrm{~A})$. They are denoted, respectively: $S_{\text {exp,55, }} S_{\text {exp,65 }}$ and $S_{\text {exp,75, and }}$ $P_{\text {exp }, 55}, P_{\text {exp,65 }}$ and $P_{\text {exp,75. }}$

- Noise sensitive centers are not only important for determining noise zoning that influences the acoustic quality objective (European Union, 2002) —it is also assumed 
that the number of sensitive centers exposed to high levels of noise on the RSPI must be taken into account just as the previous variables, rather than as a binary variable $\left(E_{S C}\right)$ (Ruiz-Padillo et al., 2014). Therefore, the formulation of this variable was adapted to the number of exposed noise sensitive centers $\left(S C_{\exp }\right)$, which is also determined in the SNM according to the corresponding intervals of levels of noise exposure. These data can thus be broken down into three sub-variables, as above, to be denoted $S C_{\text {exp,55, }} S C_{\text {exp,65 }}$ and $S C_{\text {exp }, 75 .}$

- Finally, the existence of anti-noise measures — both previously established and planned - was still considered in the variable $E_{A N M}$ (also with a binary value, i.e. 1 if there are not anti-noise measures neither already implemented nor planned, or 0 , otherwise) (Ruiz-Padillo et al., 2014).

The methodology therefore involves nine road stretch priority variables, four of them having dependent sub-variables, bringing us to a total of 16 factors, as shown in Table 1 . The RSPI is determined as a weighted sum of these parameters. So, the RSPI is defined by Eq. 4:

$$
R S P I=\sum_{i=1}^{16} R S P V_{i} \cdot w_{i}
$$

where $R S P V_{i}$ are the normalized road stretch priority variables and sub-variables; and

$w_{i}$ denotes the corresponding weights to each parameter, obtained from application of FAHP and the expert panel, as explained below.

\subsection{Fuzzy Analytic Hierarchy Process.}

There is extensive literature on the application of the Analytic Hierarchy Process developed by Saaty (AHP). This technique is easily understood, and widely used as a decision model due to both the way that multiple criteria are treated and its qualitative and quantitative data processing (Saaty, 1987; Gass and Rapscák, 2004; Mahmoodzadeh et al., 2007; García-Cascales and Lamata, 2009; Zhu and Dale, 2001). AHP is based on a concept of balance that is used to determine the overall importance of criteria about the problem at hand. Obtaining normalized weights, the main purpose of applying AHP, can be achieved by structuring the multiple criteria on hierarchical levels and assigning a 
relative significance for each level of criteria in relation to an upper level, represented by numerical comparisons in a set of matrices (Zhu and Dale, 2001; Saaty, 2002; Bottero et al., 2011; Kazakis et al., 2015; Delgado-Galván et al., 2014).

Still, AHP is not able to mimic the way human thought makes decisions (Kahraman et al., 2003; Chan and Kumar, 2007) by means of a model of uncertain and inaccurate evaluation. Taking into account the complexity and uncertainty involved in real-life problems, decision-makers tend to be imprecise in their preferences, and experts are uninclined or unable to assign accurate values when comparing various criteria (Mikhailov, 2003; Erensal et al., 2006). Furthermore, available data and information regarding the variables may be vague and ambiguous.

Hence it is particularly interesting to link traditional AHP with the fuzzy systems theory in order to harbor the concept of uncertainty that is inherent to human judgment (Buckley, 1985; Cheng, 1996; Van Laarhoven and Pedrycz, 1983; Wang et al., 2008; Rinderknecht et al., 2012). This methodological extension with the concept of fuzzy set theory as introduced by Zadeh (1965) is known in the literature as Fuzzy Analytic Hierarchy Process (FAHP). It was eventually developed as a solution for hierarchical fuzzy problems (García-Cascales and Lamata, 2009; Kahraman et al., 2003; Chan and Kumar, 2007; Lau et al., 2003).

FAHP can be discerned from traditional AHP by the following main characteristics (Mahmoodzadeh et al., 2007; García-Cascales and Lamata, 2009):

- The use of fuzzy numbers in Saaty's fundamental scale $(1 / 9,1 / 8, \ldots, 1, \ldots, 8,9)$ (Saaty, 1987) to shape expressions closer to natural language in the judgments when constructing pairwise comparison matrices.

- The use of linguistic labels to assess the relative importance of attributes, factors, conditions and/or criteria in pairwise comparisons with others of the same hierarchical level.

Of course, calculation procedures are based on the principles of the "fuzzy sets" theory, since the assessments are no longer crisp numbers.

It is important to recall that, when using FAHP for criteria weighting, a consistency ratio (C.R.) is obtained in addition to the corresponding principal eigenvector, which represents the priority vector, integrated by the intended weights (Bottero et al., 2011; Zhu and Dale, 2001; Liao, 2011; Delgado-Galván et al., 2014). The consistency 
ratio is the measure of how good this eigenvector estimates the weight vector. It is obtained by comparing the consistency index (C.I.) with the appropriate average random consistency index (R.I.), derived from a sample of size 500 from a randomly generated reciprocal matrix, using Saaty’s fundamental scale (Saaty, 1987) (Eq. 5):

$$
C . R .=\frac{C . I .}{R . I .}
$$

Values of the R.I. are obtained according to the size of the pairwise comparisons matrix (Saaty, 1987).

The C.I. of a matrix of comparisons is given by Eq. 6:

$$
\text { C.I. }=\frac{\lambda_{\max }-n}{n-1}
$$

where $\lambda_{\max }$ is the largest or principal eigenvalue of the comparison matrix; and

$n$ is the size of the matrix (number of elements of the diagonal).

If the consistency ratio is not less than $10 \%$, it is recommended to re-study the problem and review the judgments. For $n=3$ the threshold is fixed at $5 \%$, and for $n=4$ at $8 \%$.

Other fundamental aspects of implementation of the FAHP are:

i) The comparison scale through linguistic labels associated with triangular fuzzy numbers (Büyüközkan et al., 2004; Celik et al., 2009). Table 2 shows the scale used in this paper.

ii) Data aggregation. Given the utilization of the expert panel technique to obtain necessary pairwise comparisons, global judgments must be obtained through an aggregation model. Saaty proposed geometric means of aggregating pairwise valuations carried out by several experts or decision-makers (Zhu and Dale, 2001; Kazakis et al., 2015; Liao, 2011; Saaty, 1990). Moreover, the geometric mean is an acceptable, simple and rapid procedure that meets the conditions of symmetry (overall assessment is not modified if two individual valuations are exchanged), of agreement (if all individuals agree, the overall opinion correlates with them), of linear homogeneity (if each valuation of the members of the group is multiplied by a constant, the group preference is also multiplied by the constant), and of reciprocity (the average of reciprocal judgments being the unit of reference). Both the weight vector and the eigenvalue are obtained from this aggregated matrix. 
iii) The defuzzification of the fuzzy weight vector obtained from the pairwise comparisons matrix. Two fundamental versions of the FAHP can be used to get the crisp associated values: the so-called original version deploys the defuzzification technique through the fuzzy centroid or the center of gravity of a triangular fuzzy number -i.e., if $(a, b, c)$ is a triangular fuzzy number, the defuzzificated associated value is $(a+b+c)$ / 3 (Lau et al., 2003); or the approach based on Chang's extent analysis (Chang, 1996) and denominated Fuzzy Extended Hierarchy Process (FEAHP), which performs defuzzification through the measure of the possibility, as described below:

If the object set is denoted by $X=\left\{x_{1}, x_{2}, \ldots, x_{n}\right\}$ and the goal set is denoted by $G$ $=\left\{g_{1}, g_{2}, \ldots, g_{m}\right\}$, then according to the principles of Chang's extent analysis, each object is considered correspondingly, and for each object the analysis is carried out for each of the possible goals, $g_{i}$. The $m$ extent analysis values for each object are thus obtained as $\widetilde{M}_{g_{i}}^{1}, \widetilde{M}_{g_{i}}^{2}, \ldots, \widetilde{M}_{g_{i}}^{m}, i=1,2, \ldots, n$, where $\widetilde{M}_{g_{i}}^{j}(j=1,2, \ldots, m)$ are all triangular fuzzy numbers. The membership function of the triangular fuzzy number is denoted by $\mu_{\widetilde{M}}=$ $(l, u, v)$.

The steps of Chang's extent analysis can be summed up as follows (Chan and Kumar, 2007; Erensal et al., 2006; Liao, 2011; Büyüközkan et al., 2004; Celik et al., 2009; Chan et al., 2013).

Step 1: The value of fuzzy synthetic extent with respect to the ith object is defined by Eq. 7:

$$
S_{i}=\sum_{j=1}^{m} \widetilde{M}_{g_{i}}^{j} \otimes\left[\sum_{i=1}^{n} \sum_{j=1}^{m} \widetilde{M}_{g_{i}}^{j}\right]^{-1}
$$

where $\otimes$ denotes the extended multiplication of two fuzzy numbers.

The value of $\sum_{j=1}^{m} \widetilde{M}_{g_{i}}^{j}$ can be found by performing the fuzzy addition of $m$ extent analysis values for a particular matrix such that

$$
\sum_{j=1}^{m} \widetilde{M}_{g_{i}}^{j}=\left(\sum_{j=1}^{m} l_{j}, \sum_{j=1}^{m} u_{j}, \sum_{j=1}^{m} v_{j}\right)
$$

and $\left[\sum_{i=1}^{n} \sum_{j=1}^{m} \widetilde{M}_{g_{i}}^{j}\right]^{-1}$ can be expressed as

$$
\left[\sum_{i=1}^{n} \sum_{j=1}^{m} \widetilde{M}_{g_{i}}^{j}\right]^{-1}=\left(\frac{1}{\sum_{j=1}^{m} v_{j}}, \frac{1}{\sum_{j=1}^{m} u_{j}}, \frac{1}{\sum_{j=1}^{m} l_{j}}\right)
$$

where $\forall l_{i}, u_{i}, v_{i}>0$. 
Step 2: The degree of possibility of $\widetilde{M}_{2}=\left(l_{2}, u_{2}, v_{2}\right) \geq \widetilde{M}_{1}=\left(l_{1}, u_{1}, v_{1}\right)$ is defined by Eq. 10:

$$
V\left(\widetilde{M}_{2} \geq \widetilde{M}_{1}\right)=\sup _{y \geq x}\left[\min \left(\mu_{\widetilde{M}_{1}}(x), \mu_{\widetilde{M}_{2}}(x)\right)\right]
$$

and can be calculated by Eq. 11 (Fig. 1):

$$
V\left(\widetilde{M}_{2} \geq \widetilde{M}_{1}\right)=\operatorname{hgt}\left(\widetilde{M}_{2} \cap \widetilde{M}_{1}\right)=\mu_{\widetilde{M}_{2}}(d)=\left\{\begin{array}{cl}
1, & \text { if } u_{2} \geq u_{1} \\
0, & \text { if } l_{1} \geq v_{2} \\
\frac{l_{1}-v_{2}}{\left(u_{2}-v_{2}\right)-\left(u_{1}-l_{1}\right)}, & \text { otherwise }
\end{array}\right.
$$

where $d$ is the ordinate of the highest intersection point between $\mu_{\widetilde{M}_{1}}$ and $\mu_{\widetilde{M}_{2}}$. In order to compare, both the values of $V\left(\widetilde{M}_{2} \geq \widetilde{M}_{1}\right)$ and $V\left(\widetilde{M}_{1} \geq \widetilde{M}_{2}\right)$ are required.

Step 3: The degree possibility for a convex fuzzy number to be greater than $k$ convex fuzzy numbers $\widetilde{M}_{i}, i=1,2, \ldots, k$ can be defined by Eq. 12 :

$$
\begin{aligned}
& V\left(\widetilde{M} \geq \widetilde{M}_{1}, \widetilde{M}_{2}, \ldots, \widetilde{M}_{k}\right)=\mathrm{V}\left[\left(\widetilde{M} \geq \widetilde{M}_{1}\right) \text { and }\left(\widetilde{M} \geq \widetilde{M}_{2}\right) \text { and } \ldots \text { and }(\widetilde{M} \geq\right. \\
& \left.\left.\widetilde{M}_{k}\right)\right]=\min \mathrm{V}\left(\widetilde{M} \geq \widetilde{M}_{i}\right), i=1,2, \ldots, k
\end{aligned}
$$

Then, assuming that $d^{\prime}\left(A_{i}\right)=\min V\left(S_{i} \geq S_{k}\right)$, for $k=1,2, \ldots, n ; k \neq i$, the weight vector is given by $W^{\prime}=\left(d^{\prime}\left(A_{1}\right), d^{\prime}\left(A_{2}\right), \ldots, d^{\prime}\left(A_{n}\right)\right)^{T}$, where $A_{i}, i=1,2, \ldots, n$, are $n$ elements.

Step 4: Finally, via normalization, the normalized weight vector is $W=\left(d\left(A_{1}\right)\right.$, $\left.d\left(A_{2}\right), \ldots, d\left(A_{n}\right)\right)^{T}$, where $W$ is a nonfuzzy number that gives the priority weights of one attribute or alternative over another. Normalization is the fourth fundamental aspect of FAHP implementation, as will be shown below.

Subsequently, having reached the crisp weight vector, calculating its consistency depends on the principal eigenvalue of the comparisons matrix $\lambda_{\max }$, another value to be defuzzificated. In both FAHP versions, defuzzification of the eigenvalue entails choosing the central or modal value of the fuzzy number.

iv) The normalization of results is required as the final step for arriving at the intended values. This paper uses a linear procedure, which presents each value as a percentage of the total, i.e. (Eq. 13)

$$
r_{i j}=\frac{x_{i j}}{\sum_{i=1}^{m} x_{i j}}
$$


where $r_{i j}$ are normalized values and $x_{i j}$ are values obtained directly from FAHP implementation.

Both the original FAHP version and FEAHP are implemented in this paper so that their results can be compared, revealing any consistency differences.

\subsection{Expert panel.}

For the purpose of minimizing subjectivity, and in light of the impropriety of evaluations required for the pairwise comparisons used by the FAHP, despite knowing that uncertainty characterizes and motivates the use of fuzzy techniques, these assessments were obtained via questionnaires involving experts in respective decisionmaking fields (Wang et al., 2008; Rinderknecht et al., 2012; Liao, 2011; Zhu and Dale, 2001; Celik et al., 2009; Delgado-Galván et al., 2014). Among the different options that could be employed to form the expert panel, postal questionnaires were selected. A total of 21 questionnaires were sent via e-mail to technical specialists in senior management positions of the three Spanish Administrations responsible for roads, specifically in the geographical scope of Andalusia (southern Spain): state (1), regional (18) and provincial (2) levels. Three further experts from the regional administration responsible for informing/transmitting NAP to the Ministry of Environment were added to the panel.

After some instructions about the process, the nine RSPV were submitted to the experts with a brief explanation about its meaning and the adopted notation in the questionnaire. Before starting filling in the questionnaire, experts had the option to solve any doubt with the authors about the process, but not about the responses, in order to avoid biased results. Then, they were asked to sort the variables according to their relative importance in the decision-making problem of sorting road stretches by priority for action against traffic noise. They were also asked if it was necessary to consider some other variables in the problem in addition to the mentioned $R S P V$. If so, experts must fill in the appropriate field of the questionnaire with the additional variables and indicators. This procedure ensured the convenience and quality of the considered $R S P V$, and was the reason to add the vehicle speed parameter in the list. 
Subsequently, each $R S P V$ was compared with the other variables, and experts must answer with the linguistic labels defined in Table 2. A similar process was repeated with the four groups of sub-variables, until achieving all the pairwise comparisons.

Finally, each expert was asked to send back to the authors of the study his/her completed questionnaire, thanking him/her for the collaboration in the research. After the initially specified period of two months, 19 questionnaires were correctly received and processed, with participants coming from all the Administration departments.

It should be remarked that in this study, great importance was given to the composition and size of the members for the expert panel with the intention of ensuring valid and unbiased results (people who really are really involved in this problem in a road network). Therefore, technicians of the highest hierarchical level of the departments responsible for roads in the three different administrative categories in the autonomous region of Andalusia, southern Spain, were consulted. Since they are the small number of people with management responsibilities in the problem addressed here, only these group satisfies the specific characteristics required for being members of the expert panel in our study. As a result the entire population involved in the decision-making process coming from all provinces and Administration levels in the territorial scope of the expert panel were chosen. In addition, the consistency of the results was also verified according to the Fuzzy Analytical Hierarchy Process to apply the methodology and it was successful.

\section{Results and Discussion.}

\subsection{Weighting the RSPV.}

FAHP was implemented to obtain the weights applied to RSPV for calculating RSPI. It was therefore necessary to define the hierarchy system only for the levels concerning the goal and criteria (the $9 R S P V$, within the recommendations issued by Saaty for the FAHP) and sub-criteria (the various sub-variables), but not the alternative level (e.g. the different sorts of road stretch in the NAP). We strove to put forth a more generic methodology, applicable in a vast array of cases. 
The hierarchy system used in the FAHP is as shown in Fig. 2.

The pairwise comparison matrices with the relative importance fuzzy judgments of the $9 R S P V$ and their corresponding sub-variables were obtained from the geometric mean of the corresponding fuzzy elements of the comparison matrices generated from the interviewed experts’ responses, as can be seen in Fig. 3 and 4.

$R S P V$ crisp weight vectors were obtained by means of FAHP application in both versions presented above. The results, normalized and denoted in percentage, are shown below:

$$
W_{R S P \text {,original }}=\left(\begin{array}{c}
w_{\Delta L} \\
w_{P_{\text {exp }}} \\
w_{S_{\text {exp }}} \\
w_{A D T} \\
w_{0 h v} \\
w_{S} \\
w_{E_{C}} \\
w_{S C_{\text {exp }}} \\
\left.w_{E_{A N M}}\right)_{\text {original }} \\
\text { C.R. }=0.003
\end{array}\right.
$$

$$
W_{R S P V, \text { extent }}=\left(\begin{array}{c}
w_{\Delta L} \\
w_{P_{\text {exp }}} \\
w_{S_{\text {exp }}} \\
w_{A D T} \\
w_{\% h v} \\
w_{S} \\
w_{E_{C}} \\
w_{S C_{\text {exp }}} \\
\left.w_{E_{A N M}}\right)_{\text {extent }} \\
\text { C.R. }=0.005
\end{array}\right.
$$

Weights of sub-variables were obtained in the same way, from the sub-variable pairwise comparison matrices, except for sub-variables related to necessary attenuation $(\Delta L)$, because FAHP is not applicable to 2-size matrices. In this case, the only representative element of the pairwise comparison matrix was defuzzificated, and a value of the necessary attenuation sub-variables' relative importance was given. This value could be directly transformed into weights of both sub-variables; hence, we have the vectors:

$$
W_{\Delta L}=\left(\begin{array}{l}
w_{\Delta L_{d}} \\
w_{\Delta L_{n}}
\end{array}\right)=\left(\begin{array}{l}
22.27 \% \\
77.73 \%
\end{array}\right)
$$




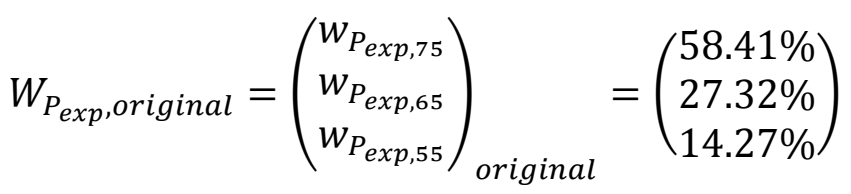

$$
\begin{aligned}
& \text { C.R. }=0.037 \\
& W_{P_{\text {exp }}, \text { extent }}=\left(\begin{array}{l}
w_{P_{\text {exp }, 75}} \\
w_{P_{\text {exp }, 65}} \\
w_{P_{\text {exp }, 55}}
\end{array}\right)_{\text {extent }}=\left(\begin{array}{c}
70.54 \% \\
29.46 \% \\
0.00 \%
\end{array}\right) \\
& \text { C. } R .=0.084 \\
& W_{S_{\text {exp }, \text { original }}}=\left(\begin{array}{l}
w_{S_{\text {exp }, 75}} \\
w_{S_{\text {exp }, 65}} \\
w_{S_{\text {exp }, 55}}
\end{array}\right)_{\text {original }}=\left(\begin{array}{l}
57.35 \% \\
27.74 \% \\
14.91 \%
\end{array}\right) \\
& \text { C. } R .=0.054 \\
& W_{S_{\text {exp }}, \text { extent }}=\left(\begin{array}{c}
w_{S_{\text {exp }, 75}} \\
w_{S_{\text {exp }, 65}} \\
w_{S_{\text {exp }, 55}}
\end{array}\right)_{\text {extent }}=\left(\begin{array}{c}
67.52 \% \\
32.48 \% \\
0.00 \%
\end{array}\right) \\
& \text { C. R. }=0.108 \\
& W_{S C_{\text {exp }} \text { original }}=\left(\begin{array}{l}
w_{S C_{\text {exp }, 75}} \\
w_{S C_{\text {exp }, 65}} \\
w_{S C_{\text {exp }, 55}}
\end{array}\right)_{\text {original }}=\left(\begin{array}{l}
58.81 \% \\
27.10 \% \\
14.09 \%
\end{array}\right) \\
& \text { C. } R .=0.045 \\
& W_{S C_{\text {exp }} \text { extent }}=\left(\begin{array}{c}
w_{S C_{\text {exp }, 75}} \\
w_{S C_{\text {exp }, 65}} \\
w_{S C_{\text {exp }, 55}}
\end{array}\right)_{\text {extent }}=\left(\begin{array}{c}
70.96 \% \\
29.04 \% \\
0.00 \%
\end{array}\right) \\
& \text { C. } R .=0.101
\end{aligned}
$$

Consistency ratios (Eq. (5)) were obtained for each weight set. In the case of the $R S P V$ weight vectors, consistency ratio values are seen to be much lower than 0.10 , the threshold proposed by Saaty to ensure consistency of results. That is, the achieved weighting was perceived as very robust, especially with the application of the original FAHP method. In the case of $P_{\exp }, S_{\exp }$ and $S C_{\exp }$ sub-variables, results after applying FAHP extent analysis method do not present adequate consistency, since their C.R. values were higher than 0.05 (limit established for $n=3$ ). However, the consistency ratios obtained for the original FAHP method results were lower than 5\%, the exception being the exposed surface sub-variables (yet very close to this value). FAHP original method results were therefore more appropriately estimated in terms of consistency. In terms of weight values, the RSPV sets proved to be very similar in the established order and in their numeric values - although it is also important to note that in the case of the extent 
analysis method, the $S_{\text {exp }}$ variable was removed (zero weight). For sub-variable results entailing extent analysis, exposure parameters for the interval of $L_{d e n}$ between 55 and 65 $\mathrm{dB}(\mathrm{A})$ sub-variables were also removed.

In light of a literature review including consideration of the reference standards for developing NAP, we opted not to eliminate the influence of the exposed surface variable (particularly relevant in SNM), nor the influence of exposure to sound levels below $65 \mathrm{~dB}(\mathrm{~A})$ parameters, which would imply dismissing an important part of the acoustic impact.

Therefore, weight vectors obtained by means of the original FAHP, combined with defuzzification by the fuzzy centroid, were held to be more adequate as weight values for the $R S P V$ and sub-variables in the context of the proposed methodology.

Finally, sub-variable weights (relative to the objective upper level) were derived by aggregation under the established hierarchy, simply by multiplying the sub-criteria weight sets by the corresponding criterion weight (Bottero et al., 2011; Liao, 2011; Zhu and Dale, 2001). Accordingly, as the main results achieved in this work, the values weighting each variable within the RSPI (Eq. (4)) are shown in Table 3. These weights may be used in any Road Noise Action Plan analysis, and regardless of the origin of the data employed to assess the RSPV, the calculation tool or the Road Network size.

Based on the values of the weightings obtained, the variables "exposed population to more than $75 \mathrm{~dB}(\mathrm{~A})$ of $L_{d e n}$ ”, “ADT”, “attenuation of sound level in night periods” and "number of sensitive-centers exposed to $L_{d e n}$ above $75 \mathrm{~dB}(\mathrm{~A})$ ” were found to be the most influential variables for prioritizing road stretches. In other words, the variables having the most substantial effect on the population, according to the consensus of the expert panel, were the variables with the greatest weighting in the decision-making methodology. This result would appear to be consistent with the primary objective of NAP's formulation, regarding which road stretches are to be prioritized, and with the philosophy behind the European Environmental Noise Directive as well as recommendations issued at the European level for prioritization in actions against noise (Silence project, 2009; IMAGINE project, 2004; De Vos, 2009). 
3.2. Illustrative case: Application to priority review of road stretches from the Regional Noise Action Plan 2008-2012 within the province of Almería (Andalusia, Spain).

To illustrate the methodology developed in this paper, we offer a case study of the Andalusian Regional Road Network in the province of Almería. The present results were compared with those published in a previous paper (Ruiz-Padillo et al., 2014). The road stretches chosen for the case study have a greater $A D T$ and population living nearby (COFV, 2014), or else citizens’ complaints accurately reflect road traffic noise at certain locations:

- A-1000 road, which runs from N-340a in "Huércal de Almería” to A-7 in "Viator", in the stretch between km 0+350 and km 1+100;

- A-1051 motorway, in the stretch from A-7 in “Aguadulce” to "El Parador de las Hortichuelas”, from km 0+400 to km 2+300; and

- A-1201 road, in the stretch between the center and the northern exit to "Pulpí", which received recurring complaints from citizens about road traffic noise in neighboring dwellings, from km 13+700 to km 13+800.

The specific location of the studied road stretches can be seen in Figure 5, as well as the RSPI index for each one.

$R S P V$ values for the studied road stretches, obtained from SNM data elaborated by the Regional Administration (“Junta de Andalucía”) in 2014, are summarized in Table 4 (COFV, 2014). It includes the calculated values for each RSPV after normalization (Eq. (13)) and multiplication by weights listed in Table 3, as well as the resulting RSPI (Eq. (4)) for each road stretch. These index values facilitate sorting by priority for action in the corresponding NAP.

The priority order for action that should be given to the road stretches within the NAP 2008-2012 of the regional road in the province of Almería (in the corresponding review at the present time: A-1000, A-1051 and A-1201) is provided by the calculated RSPI values.

The methodology pointed to highest priority for action for the A-1000 road stretch. In fact, this was the only stretch of the regional road network of Almería that was included 
in the NAP formulated in 2008 (COPT, 2008)). Its traffic volume has since dropped from 6,000,000 vehicles/year (the threshold for the obligation to be included in NAP in 2008).

Despite showing the highest ADT value, the A-1051 motorway stretch was not considered by the Regional Administration in the first phase of the implementation of the Directive. Consequently it was not included under the needs for prompt action of the published plan.

The A-1201 road stretch received the lowest priority, although the Regional Administration was not obliged to include it in the action plan by strictly applying the Environmental Noise Directive.

From the values of the RSPV (in the estimation of the $R S P I$ ) for the three stretches studied, it is observed that:

- High priority of the A-1000 road stretch was significantly influenced by the high sound level affecting the population (even over $75 \mathrm{~dB}(\mathrm{~A})$ ) and by the existence of a school (noise-sensitive center) above the $55 \mathrm{~dB}(\mathrm{~A})$ level of $L_{d e n}$.

- The RSPI value reached by the A-1051 road stretch mostly responds to its high traffic data ( $A D T$, percentage of heavy vehicles and speed of vehicles), and the larger surface exposed to high sound levels; notwithstanding, it already had a noise barrier along its entire length and had a less adverse effect on the population.

- In relation to the A-1201 road stretch, it was found that the most important factors comparatively contributing to the final value of its $R S P I$ were mainly the occurrence of citizens' complaints, and to a lesser extent, the percentage of heavy vehicles and the speed of the vehicles, which were higher than on the other stretches (excepting the speed on A1051, somewhat greater, but not as high as might be expected for a motorway). Apart from having less $A D T$, the small population exposed to noise essentially reduces urgency for action. We should stress, however, that the Regional Administration has already planned noise barriers to mitigate existing noise due to the road traffic in neighboring dwellings whose inhabitants have submitted complaints about it in this area. For this reason, and even though road stretch A-1201 has the lowest priority for action in the NAP, it seems appropriate to include A-1201 in the budget planning for the period of validity of the NAP. A solution for annoying noise would thus be ensured for the citizens having filed complaints, as for the other two road stretches. 
The road stretches of this case study were sorted with the same priority achieved using weights estimated in the methodology design (Ruiz-Padillo et al., 2014), although RSPI values obtained have changed, especially for the A-1051 road stretch. The results in the illustrative case remain equally logical in both applications; and having checked the robustness of the developed methodology, the greater validity of the results is highlighted by the accuracy of the weight set used. Moreover, classifications by priority as derived through this methodology are enhanced by a more objective and reasoned basis, supported by previous expert opinions and FAHP use.

Another noteworthy outcome in this illustrative case stems from our comparison of the priority established by applying the proposed methodology and the classifications offered by interviewed experts. All the experts consulted coincided in sorting the three road stretches with the same priority. This stands as proof of the accuracy and consistency of the obtained results.

Methodological validation can be soundly based on the techniques used and the case study analyzed in this work. Once road stretches that require planning solutions against road traffic noise have been sorted according to by priority in the NAP, it is possible to examine suitable alternatives and choose the most suitable option in accordance with the second phase of the proposed methodology, as described in RuizPadillo et al. (2014). This decision-making problem is again of the multicriteria analysis type and is applied to the pre-selected alternatives. Of course, this choice should be reasoned and justified, meaning further research is necessary to determine criteria and their relative influence in this phase. Subsequently, actions for estimating total cost distribution should be carried out within the period of NAP validity, taking into account prioritization as established by the RSPI calculated values.

\section{Conclusions.}

The development and implementation of a multi-criteria methodology for decision-making were deemed necessary for the classification by priority for action of road stretches included under Noise Action Plans, mainly in terms of the weights assigned to Road Stretch Priority Variables (RSPV) for Road Stretch Priority Index (RSPI) 
formulation. Given the complexity of the decisions to be made and the associated uncertainty in decision-making, the Fuzzy Analytic Hierarchy Process was adopted as the most practical approach. This multi-criteria decision-making method was applied to results from an expert panel, through questionnaires given to specialists with appropriate knowledge and experience in the raised issues.

The methodology developed in this work made it possible to obtain RSPV weights in the context of RSPI calculation in a more objective way. This sound foundation implies a broader application capacity for the methodology. For instance, it might be useful for policy-makers elaborating Noise Action Plans for any Road Network. Managers can decide about the prioritization of the road stretches included in a certain Noise Action Plan, simply by comparing their RSPI values with each other. For this, they must evaluate the RSPV and sub-variables from traffic and SNM data of each stretch, in addition to information of possible complaints about traffic noise. The RSPI is obtained by weighting the normalized $R S P V$ values with the weights proposed in this paper (Table 3), and then adding them up (eq. 4). Widely circulated math softwares, such as spreadsheets, can easily implement this process.

The accuracy and quality of our proposal were confirmed through a comparison of results achieved in a previously estimated application. This improved methodology presented here ensures a well-founded weighting of the variables involve in the prioritization of road-traffic stretches, allowing a high extrapolation/generalization ability of the method. The methodology was implemented in a review of the Noise Action Plan for the Andalusian Road Network within the province of Almería (southern Spain). In fact, the methodology lends objectivity and rigor to the decision-making process in road stretch prioritization, supporting valuable arguments for the adoption and implementation of the Noise Action Plan, as well as public opinion (as required by European Environmental Noise Directive).

The application of the presented methodology is possible regardless of the noise simulation technique used, and has been shown a very useful tool for subsequent stages of implementation of the European Environmental Noise Directive, especially when the CNOSSOS-EU method will be adopted as the method of generation of the strategic noise maps in 2017.

The success of the approach described here, applied to road stretch classification by priority, points to its utility in associated realms. One future research aim is the 
establishment of a weighted multicriteria method for the choice of suitable alternatives against road noise in each particular stretch of the NAP. Indeed, studying the influence of fuzzy logic on criteria and alternatives determined for such a particular problem is viewed as a highly interesting research proposal.

\section{Acknowledgments.}

This work was supported by the "Ministerio de Economía y Competitividad" of Spain under project TEC2012-38883-C02-02.

This work is also funded by the University of Malaga and the European Commission under the Agreement Grant no. 246550 of the seventh Framework Programme for R \& D of the EU, granted within the People Programme, "Co-funding of Regional, National and International Programmes" (COFUND), and "Ministerio de Economía y Competitividad” of Spain (COFUND2013-40259).

The authors wish to thank the "Dirección General de Infraestructuras de la Consejería de Fomento y Vivienda” of the “Junta de Andalucía” (Spain) for facilitating access to the data required for this study and the reviewers for their valuable comments.

\section{References.}

Bottero, M., Comino, E., Riggio, V., 2011. Application of the Analytic Hierarchy Process and the Analytic Network Process for the assessment of different wastewater treatment systems. Environmental Modelling \& Software 26, 1211-1224.

Brown, C.B., Elms, D.G., 2015. Engineering decisions: Information, knowledge and understanding. Structural Safety 52, 66-77.

Buckley, J.J., 1985. Fuzzy hierarchical analysis. Fuzzy Sets and Systems 17(3), 233-247.

Büyüközkan, G., Kabraman, C., Ruan, D., 2004. A fuzzy multi-criteria decision approach for software development strategy selection. International Journal of General Systems 33(2), 259-280. 
Celik, M., Er, I.D., Ozok, A.F., 2009. Application of fuzzy extended AHP methodology on shipping registry selection: The case of Turkish maritime industry. Expert Systems with Applications 36, 190-198.

Chan, F.T.S., Kumar, N., 2007. Global supplier development considering risk factors using fuzzy extended AHP-based approach. Omega 35, 417-431.

Chan, H., Wang, X., White, G.R.T., Yip, N., 2013. An Extended Fuzzy-AHP Approach for the Evaluation of Green Product Designs. IEEE Transactions on Engineering Management 60 (2), 327-339.

Chang, D.-Y., 1996. Applications of the extent analysis method on fuzzy AHP. European Journal of Operational Research 96, 649-655.

Cheng, C.H., 1996. Evaluating naval tactical missile systems by fuzzy-AHP based on the grade value of membership function. European Journal of Operational Research 96, 343350.

Consejería de Fomento y Vivienda de la Junta de Andalucía (COFV), 2014. Plan General de Aforos de Andalucía. 2014. [Road occupancy and traffic data. General Plan for Andalusia].

Consejería de Obras Públicas y Transportes de la Junta de Andalucía (COPT), 2008. Plan de Acción Contra el Ruido de la Red Autonómica de Carreteras de Andalucía con tráfico superior a seis millones de vehículos al año. 2008. [Action Plan Against Noise of the Regional Road Network of Andalusia with more than six million vehicles/year].

D'Alessandro, F., Schiavoni, S., 2015. A review and comparative analysis of European priority indices for noise action plans. Science of the Total Environment 518-519, 290301.

Delgado-Galván, X., Izquierdo. J., Benítez, J., Pérez-García, R., 2014. Joint stakeholder decision-making on the management of the Silao-Romita aquifer using AHP. Environmental Modelling \& Software 51, 310-322.

De Vos, P., 2008. Strategies for noise action plans. Proceedings of Euronoise Paris, France 2008. 
De Vos, P., 2009. Environmental noise directive: do's and don'ts for the second round Proceedings of Euronoise Edinburgh, Scotland 2009.

Erensal, Y.C., Öncan, T., Demircan, M.L., 2006. Determining key capabilities in technology management using fuzzy analytic hierarchy process: A case study of Turkey. Information Sciences 176, 2755-2770.

European Commission Working Group. Assessment of exposure to noise (WG-AEN), 2007. Good practice for strategic noise mapping and the production of associated data on noise exposure. Version 2. August, 2007.

European Environmental Agency (EEA), 2014. Noise in Europe 2014. http://www.eea.europa.eu/publications/noise-in-europe-2014/at_download/file

European Union, 2002. Directive 2002/49/EC of the European Parliament and of the Council of 25 June 2002 relating to the assessment and management of environmental noise. Official Journal L 189, 18/07/2002, P. 0012-0026.

García-Cascales, M.S., Lamata, M.T., 2009. Selection of a cleaning system for engine maintenance based on the analytic hierarchy process. Computers \& Industrial Engineering 56(4), 1442-1451.

Gass, S.I., Rapcsák, T., 2004. Singular value decomposition in AHP. European Journal of Operational Research 154, 573-584.

IMAGINE Project, 2004. Improved methods for the assessment of the generic impact of noise in the environment. State of the art. IMAGINE report IMA10TR-040423AEATNL32, 14 October 2004.

Kahraman, C., Cebeci, U., Ulukan, Z., 2003. Multi-criteria supplier selection using fuzzy AHP. Logistics Information Management 16(6), 382-394.

Kazakis, N., Kougias, I., Patsialis, T., 2015. Assessment of flood hazard areas at a regional scale using an index-based approach and Analytical Hierarchy Process: Application in Rhodope-Evros region, Greece. Science of the Total Environment 538, 555-563. 
Lau, H.C.W., Wong, C.W.Y., Lau, P.K.H., Pun, K.F., Chin, K.S., Jiang, B., 2003. A fuzzy multi-criteria decision support procedure for enhancing information delivery in extended enterprise networks. Engineering Applications of Artificial Intelligence 16, 1-9.

Liao, C.-N., 2011. Fuzzy analytical hierarchy process and multi-segment goal programming applied to new product segmented under price strategy. Computers \& Industrial Engineering 61, 831-841.

Licitra, G., Ascari, E., Brambilla, G., 2012. Comparative Analysis of Methods to Estimate Urban Noise Exposure of Inhabitants. Acta Acustica united with Acustica 98 (4), 659666.Licitra, G., Ascari, E., 2014. Gden: An indicator for European noise maps comparison and to support action plans. Science of the Total Environment 482, 411-419.

Licitra, G., Gallo, P., Rossi, E., Brambilla, G., 2011. A novel method to determine multiexposure priority indices tested for Pisa action plan, Applied Acoustics 72 (8), 505510.

Mahmoodzadeh, S., Shahrabi, J., Pariazar, M., Zaeri, M.S., 2007. Project selection by using fuzzy AHP and TOPSIS technique. International Journal of Humanities and Social Sciences 1(3), 135-140.

Mikhailov, L., 2003. Deriving priorities from fuzzy pairwise comparison judgements. Fuzzy Sets and Systems 134(3), 365-385.

Milieu Ltd., Risk and Policy Analysis Ltd., TNO, 2010. Review of the Implementation of Directive 2002/49/EC on Environmental Noise. Final report.

Naish, D., 2010. A method of developing regional road traffic noise management strategy. Applied Acoustics 71, 640-652.

Ouis, D., 2001. Annoyance from road traffic noise: a review. J. Environ. Psychol 21, 101120.

Rinderknecht, S.L., Borsuk, M.E., Reichert, P., 2012. Bridging uncertain and ambiguous knowledge with imprecise probabilities. Environmental Modelling \& Software 36, 122130. 
Ruiz-Padillo, A., Torija, A.J., Ramos-Ridao, Á., Ruiz. D.P., 2014. A methodology for classification by priority for action: selecting road stretches for network noise action plans. Transportation Research Part D 29, 66-78.

Saaty, R.W., 1987. The Analytic Hierarchy Process - What it is and how it is used. Mathl Modelling 9(3-5), 161-176.

Saaty, T.L., 1990. How to Make a Decision. European Journal of Operational Research 48, 9-26.

Saaty, T.L., 2002. Decision making with the analytic hierarchy process. Scientia Iranica 9(3), 215-229.

Silence Project, 2009. Silence: Practitioner handbook for local noise action plans. www.silence-ip.org/site

Torija, A.J., Genaro, N., Ruiz, D.P., Ramos-Ridao, Á., Zamorano, M., Requena, I., 2010. Priorization of acoustic variables: environmental decision support for the physical characterization of urban sound environments. Building and Environment 45, 1477-1489.

Van Laarhoven, P.J.M., Pedrycz, W., 1983. A fuzzy extension of Saaty's priority theory. Fuzzy Sets and Systems 11(1-3), 199-227.

Wang, Y.-M., Luo, Y., Hua, Z., 2008. On the extent analysis method for fuzzy AHP and its applications. European Journal of Operational Research 186, 735-747.

World Health Organization (WHO), 2011. Burden of disease from environmental noise. WHO and JRC, Bonn, 2011.

Zadeh, L.A., 1965. Fuzzy Sets. Information and Control 8(3), 338-353.

Zhu, X., Dale, A.P., 2001. JavaAHP: a web-based decision analysis tool for natural resource and environmental management. Environmental Modelling \& Software 16, 251262. 
Table 1: List of road stretch priority variables and sub-variables.

Table 2: Triangular scale of conversion of linguistic variables to fuzzy numbers.

Table 3: Weighting of the RSPV and sub-variables.

Table 4: Calculation of the RSPV and the RSPI values for the road stretches analyzed in the illustrative case for application of the proposed methodology. 
Table 1:

\begin{tabular}{|c|c|c|c|c|}
\hline No. & \multicolumn{2}{|c|}{ Road stretch priority variables } & \multicolumn{2}{|c|}{ Road stretch priority sub-variables } \\
\hline 1 & \multirow{2}{*}{$\Delta L$} & \multirow{2}{*}{ Noise level of necessary attenuation } & Daytime period & $\Delta L_{d}$ \\
\hline 2 & & & Night period & $\Delta L_{n}$ \\
\hline 3 & \multirow{3}{*}{$P_{\text {exp }}$} & \multirow{3}{*}{ Exposed population } & to $L_{d e n}>75 \mathrm{~dB}(\mathrm{~A})$ & $P_{\text {exp }, 75}$ \\
\hline 4 & & & to $L_{d e n} \in[65,75[\mathrm{~dB}(\mathrm{~A})$ & $P_{\text {exp }, 65}$ \\
\hline 5 & & & to $L_{d e n} \in[55,65[\mathrm{~dB}(\mathrm{~A})$ & $P_{\text {exp }, 55}$ \\
\hline 6 & \multirow{3}{*}{$S_{\text {exp }}$} & \multirow{3}{*}{ Exposed surface } & to $L_{d e n}>75 \mathrm{~dB}(\mathrm{~A})$ & $S_{\text {exp }, 75}$ \\
\hline 7 & & & to $L_{d e n} \in[65,75[\mathrm{~dB}(\mathrm{~A})$ & $S_{\text {exp }, 65}$ \\
\hline 8 & & & to $L_{d e n} \in[55,65[\mathrm{~dB}(\mathrm{~A})$ & $S_{\text {exp,55 }}$ \\
\hline 9 & $A D T$ & \multicolumn{3}{|l|}{ Average daily traffic } \\
\hline 10 & $\% h v$ & \multicolumn{3}{|l|}{ Percentage of heavy vehicles } \\
\hline 11 & $S$ & \multicolumn{3}{|l|}{ Average speed of vehicles } \\
\hline 12 & $E_{C}$ & \multicolumn{3}{|c|}{ Occurrence of citizens' traffic noise complaints } \\
\hline 13 & \multirow{3}{*}{$S C_{e x p}$} & \multirow{3}{*}{ Exposed noise-sensitive centers } & to $L_{d e n}>75 \mathrm{~dB}(\mathrm{~A})$ & $S C_{\text {exp }, 75}$ \\
\hline 14 & & & to $L_{d e n} \in[65,75[\mathrm{~dB}(\mathrm{~A})$ & $S C_{\text {exp }, 65}$ \\
\hline 15 & & & to $L_{d e n} \in[55,65[\mathrm{~dB}(\mathrm{~A})$ & $S C_{\text {exp }, 55}$ \\
\hline 16 & $E_{A N M}$ & \multicolumn{3}{|c|}{ Existence of previous measures of acoustic attenuation } \\
\hline
\end{tabular}


Table 2:

\begin{tabular}{|l|l|l|l|}
\hline $\begin{array}{c}|c| \\
\text { Intensity of } \\
\text { importance on an } \\
\text { absolute scale }\end{array}$ & Linguistic label associated & \multicolumn{1}{|c|}{$\begin{array}{l}\text { Triangular } \\
\text { fuzzy scale }\end{array}$} & $\begin{array}{l}\text { Triangular fuzzy } \\
\text { reciprocal scale }\end{array}$ \\
\hline & Exactly the same & $(1,1,1)$ & $(1,1,1)$ \\
\hline 1 & Equally important & $(1 / 2,1,2)$ & $(1 / 2,1,2)$ \\
\hline 2 & Moderately more important & $(1,2,3)$ & $(1 / 3,1 / 2,1)$ \\
\hline 3 & More important & $(2,3,4)$ & $(1 / 4,1 / 3,1 / 2)$ \\
\hline 4 & Much more important & $(3,4,5)$ & $(1 / 5,1 / 4,1 / 3)$ \\
\hline 5 & Extremely more important & $(4,5,5)$ & $(1 / 5,1 / 5,1 / 4)$ \\
\hline
\end{tabular}


Table 3:

\begin{tabular}{|c|c|c|c|c|c|}
\hline \multirow{2}{*}{$\begin{array}{c}\text { No. } \\
1\end{array}$} & \multicolumn{2}{|c|}{$\begin{array}{l}\text { Road stretch priority } \\
\text { variables }\end{array}$} & \multicolumn{2}{|c|}{ Road stretch priority sub-variables } & \multirow{2}{*}{$\begin{array}{c}\begin{array}{c}\text { Total weight } \\
(\mathbf{\%})\end{array} \\
12.26 \%\end{array}$} \\
\hline & \multirow{3}{*}{$P_{\text {exp }}$} & \multirow{3}{*}{ Exposed population } & to $L_{d e n}>75 \mathrm{~dB}(\mathrm{~A})$ & $P_{\text {exp }, 75}$ & \\
\hline 2 & & & to $L_{d e n} \in[65,75[\mathrm{~dB}(\mathrm{~A})$ & $P_{\text {exp }, 65}$ & $5.74 \%$ \\
\hline 3 & & & to $L_{d e n} \in[55,65[\mathrm{~dB}(\mathrm{~A})$ & $P_{\text {exp,55 }}$ & $3.00 \%$ \\
\hline 4 & \multirow{3}{*}{$S C_{\text {exp }}$} & \multirow{3}{*}{$\begin{array}{l}\text { Exposed noise- } \\
\text { sensitive centers }\end{array}$} & to $L_{d e n}>75 \mathrm{~dB}(\mathrm{~A})$ & $S C_{\text {exp, } 75}$ & $11.16 \%$ \\
\hline 5 & & & to $L_{d e n} \in[65,75[\mathrm{~dB}(\mathrm{~A})$ & $S C_{\text {exp,65 }}$ & $5.14 \%$ \\
\hline 6 & & & to $L_{d e n} \in[55,65[\mathrm{~dB}(\mathrm{~A})$ & $S C_{\text {exp }, 55}$ & $2.67 \%$ \\
\hline 7 & \multirow{2}{*}{$\Delta L$} & \multirow{2}{*}{$\begin{array}{l}\text { Noise level of } \\
\text { necessary attenuation }\end{array}$} & Daytime period & $\Delta L_{d}$ & $3.29 \%$ \\
\hline 8 & & & Night period & $\Delta L_{n}$ & $11.48 \%$ \\
\hline 9 & $A D T$ & \multicolumn{3}{|l|}{ Average daily traffic } & $11.60 \%$ \\
\hline 10 & $E_{C}$ & \multicolumn{3}{|c|}{ Occurrence of citizens' traffic noise complaints } & $9.05 \%$ \\
\hline 11 & $S$ & \multicolumn{3}{|c|}{ Average speed of vehicles } & $6.21 \%$ \\
\hline 12 & $\% h v$ & \multicolumn{3}{|c|}{ Percentage of heavy vehicles } & $6.63 \%$ \\
\hline 13 & $E_{\text {ANM }}$ & \multicolumn{3}{|c|}{ Existence of previous measures of acoustic attenuation } & $6.62 \%$ \\
\hline 14 & \multirow{3}{*}{$S_{\text {exp }}$} & \multirow{3}{*}{ Surface exposed } & to $L_{d e n}>75 \mathrm{~dB}(\mathrm{~A})$ & $S_{\text {exp }, 75}$ & $2.95 \%$ \\
\hline 15 & & & to $L_{d e n} \in[65,75[\mathrm{~dB}(\mathrm{~A})$ & $S_{\text {exp }, 65}$ & $1.43 \%$ \\
\hline 16 & & & to $L_{d e n} \in[55,65[\mathrm{~dB}(\mathrm{~A})$ & $S_{\text {exp }, 55}$ & $0.77 \%$ \\
\hline & & & & TOTAL & $100.00 \%$ \\
\hline
\end{tabular}


Table 4:

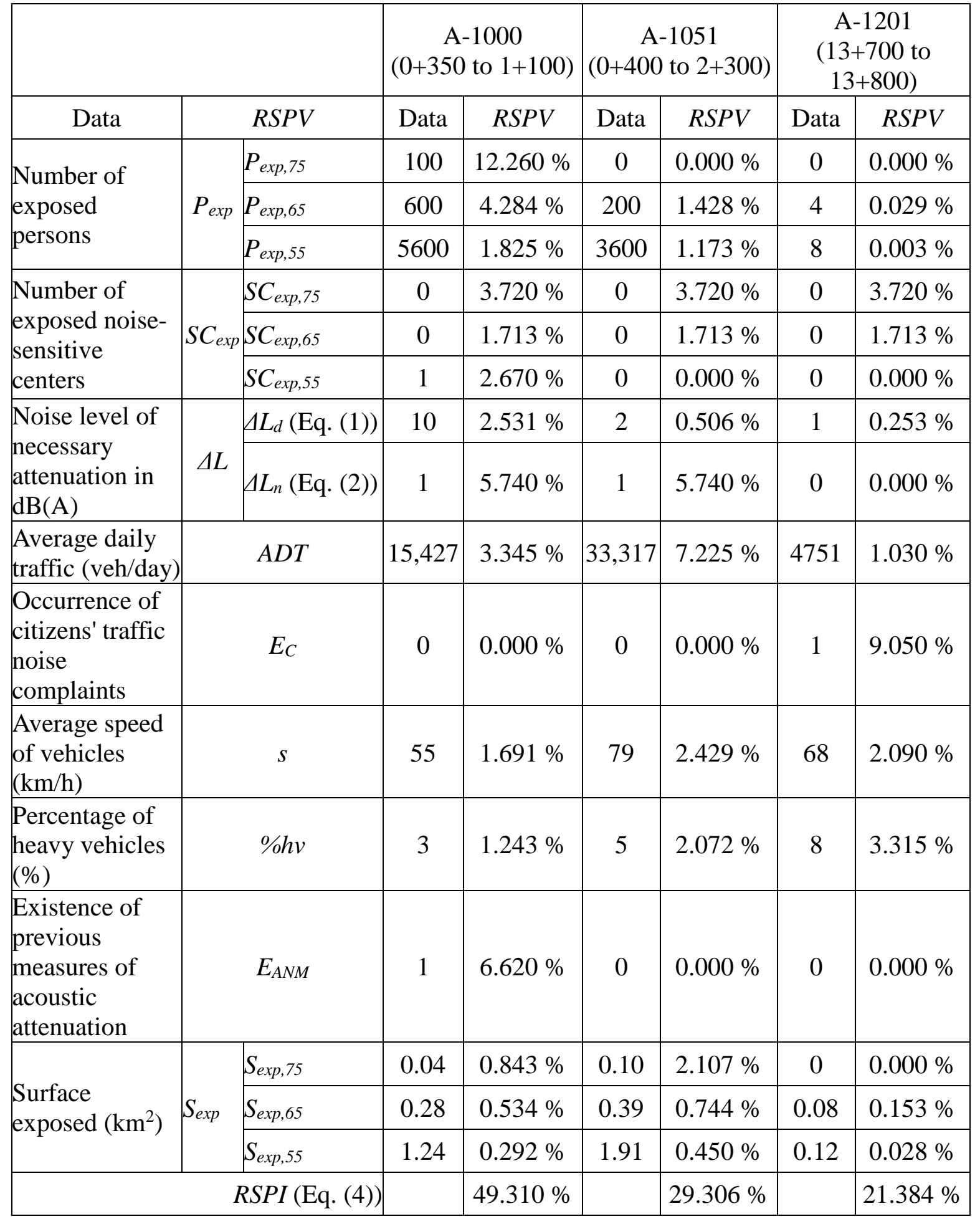


Fig. 1: The degree of possibility of $\tilde{M}_{2} \geq \tilde{M}_{1}$. Adapted from Erensal et al. (2006).

Fig. 2: Hierarchy system for criteria and sub-criteria FAHP weighting.

Fig. 3: $R S P V$ fuzzy comparison matrix.

Fig. 4: Sub-variables fuzzy comparison matrix.

Fig. 5: Location and RSPI values of the road stretches analyzed in the case study. 
Fig. 1:

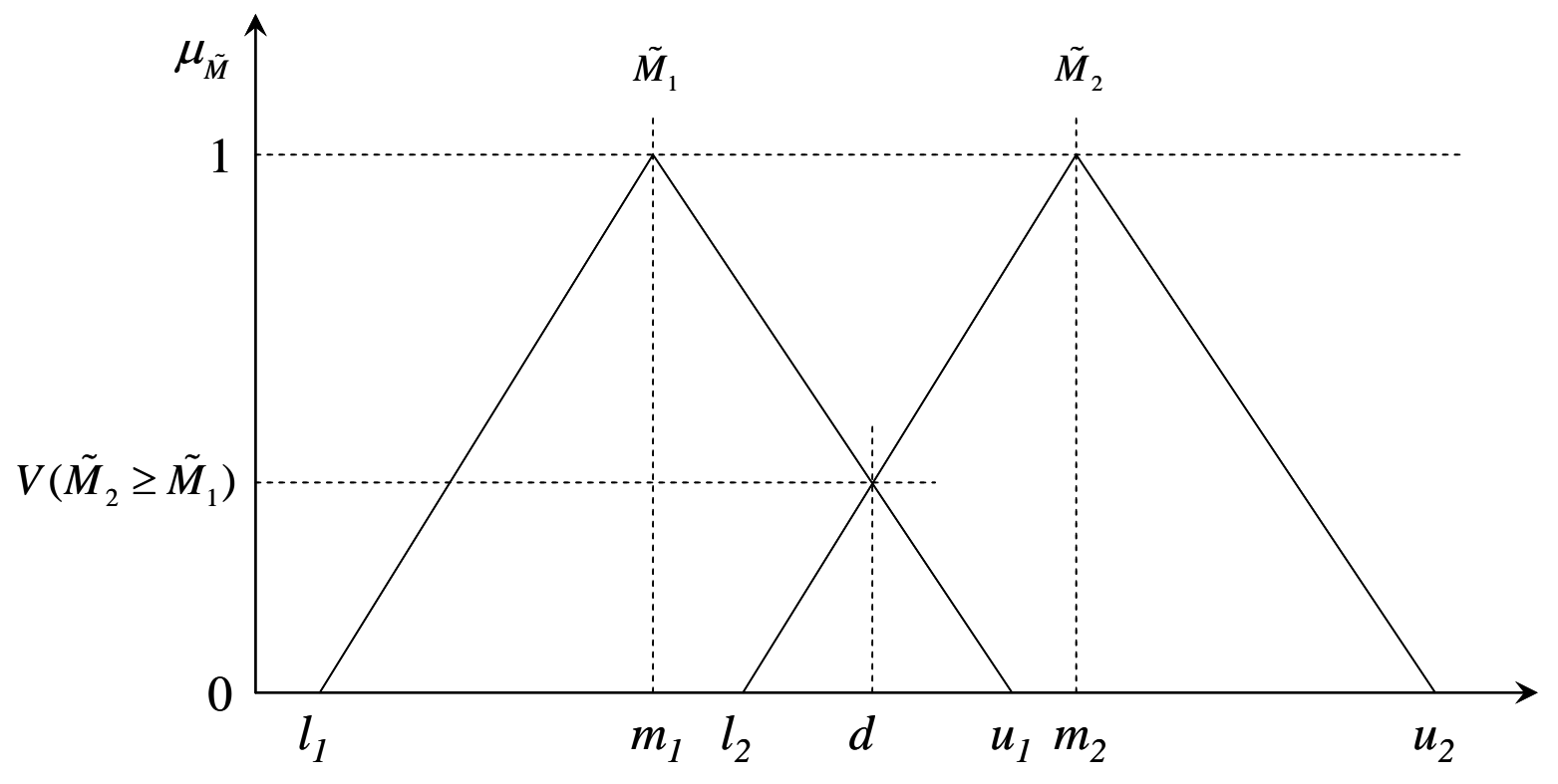




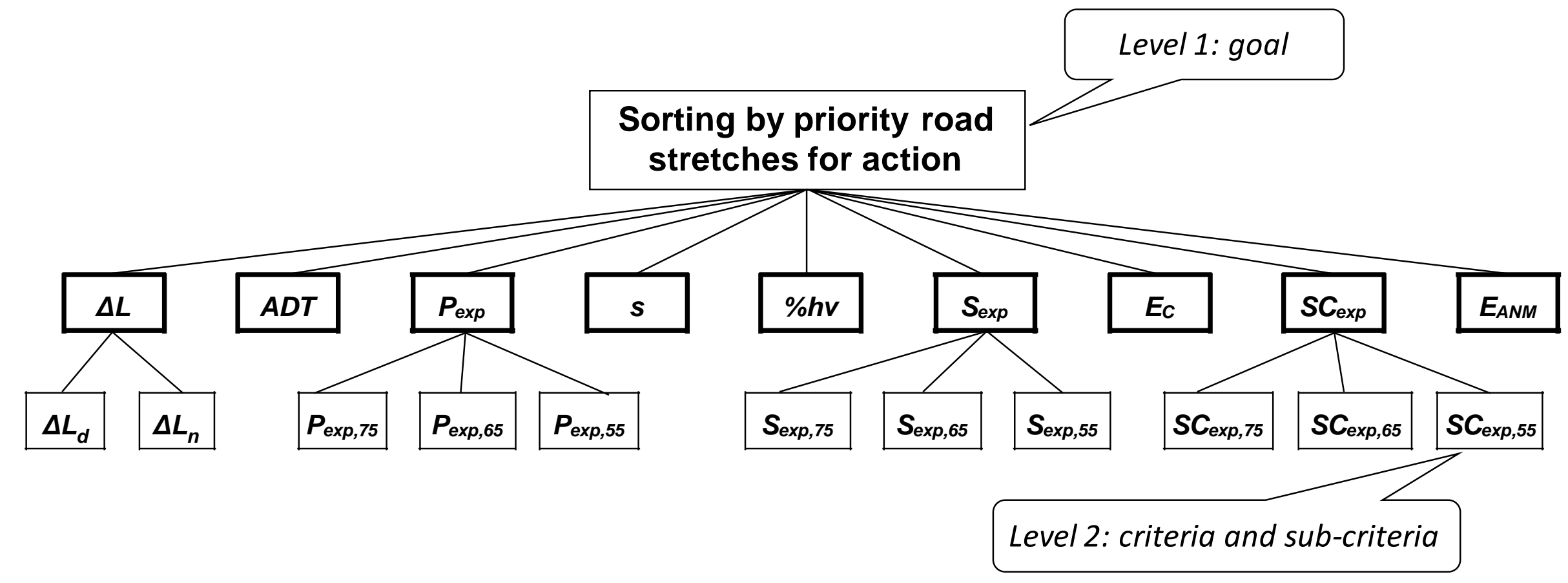


Fig 3: $\Delta L$ $P_{\text {exp }}$ $S_{\text {exp }}$

$A D T$

$\% h v$

$\begin{array}{llll}(0.420,0.638,1.053) & (1.935,2.808,3.692) & (0.876,1.411,2.086) & (1.441,2.335,3.228) \\ (1.000,1.000,1.000) & (2.670,3.743,4.468) & (1.458,2335,3.277) & (2.273,3.290,4.22)\end{array}$ $\begin{array}{lllll}(1.000,1.000,1.000) & (2.670,3.743,4.468) & (1.458,2.335,3.277) & (2.273,3.290,4.222)\end{array}$ $(1.000,1.000,1.000)$ $(0.950,1.568,2.383)$ $(0.271,0.356,0.517) \quad(0.224,0.267,0.374)$ $(0.479,0.709,1.142)$ $(0.310,0.428,0.694)$ $(0.274,0.378,0.593)$ $(0.415,0.634,0.990)$
$(0.836,1.343,2.006)$ $(0.305,0.428,0.686)$

$(0.237,0.304,0.440)$

$(1.000,1.000,1.000) \quad(0.333,0.456,0.684)$

$(0.502,0.698,1.034)$

$(1.140,1.988,3.050)$

$\begin{array}{llll}(0.226,0.286,0.406) & (0.900,1.294,1.815) & (0.307,0.454,0.782)\end{array}$

$(0.836,1.343,2.006)$
$(0.312,0.429,0.680)$

$\begin{array}{lll} & (1.373,1.868,2.363) & (0.504,0.760,1.185) \\ (0.528,0.808,1.334) & (2.467,3.521,4.258) & (1.245,1.859,2.674)\end{array}$

$\begin{array}{ccc}(0.528,0.808,1.334) & (2.467,3.521,4.258) & (1.245,1.859,2.674) \\ (0.279,0.381,0.584) & (0.849,1.243,1.833) & (0.343,0.479,0.740)\end{array}$

$(1.000,1.000,1.000)$

$(0.550,0.950,1.617)$

$(0.962,1.569,2.218)$

$(0.616,0.985,1.489)$

$(1.010,1.577,2.409) \quad(0.499,0.745,1.196)$

$\begin{array}{lllll}(0.551,0.773,1.111) & (0.423,0.535,0.728) & (0.235,0.284,0.405) & (0.456,0.804,1.178)\end{array}$

$\begin{array}{lllll}(1.279,2.204,3.259) & (0.844,1315,1.982) & (0.374,0.538,0.803) & (1.352,2.086,2.919)\end{array}$

$\begin{array}{lllll}(0.619,1.053,1.819) & (0.451,0.638,1.039) & (0.249,0.326,0.473) & (0.672,1.015,1.624)\end{array}$

(1.000,1.000,1.000) $(0.439,0.675,1.099)-(0.249,0.312,0.452)-(0.650,0.955,1.500)$

$\begin{array}{llll}(0.910,1.480,2.278) & (1.000,1.000,1.000) & (0.294,0.414,0.665) & (0.894,1.414,2.053)\end{array}$

$\begin{array}{lllll}(2.211,3.210,4.023) & (1.503,2.414,3.399) & (1.000,1.000,1.000) & (1.995,3.040,3.988)\end{array}$

$(0.667,1.047,1.539) \quad(0.487,0.707,1.118) \quad(0.251,0.329,0.501)$

$(1.000,1.000,1.000)$ 
Fig. 4:

$$
\begin{aligned}
& \Delta L_{d}
\end{aligned}
$$

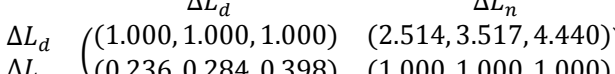

$$
\begin{aligned}
& \Delta L_{n}((0.236,0.284,0.398) \quad(1.000,1.000,1.000)) \\
& P_{\text {exp }, 75} \\
& P_{\text {exp. } 65} \\
& P_{\text {exp. } 55} \\
& S_{\text {exp }, 75} \\
& S_{\text {exp }, 65} \\
& S_{\text {exp }, 55} \\
& S C_{\text {exp } 75}
\end{aligned}
$$


Fig. 5:
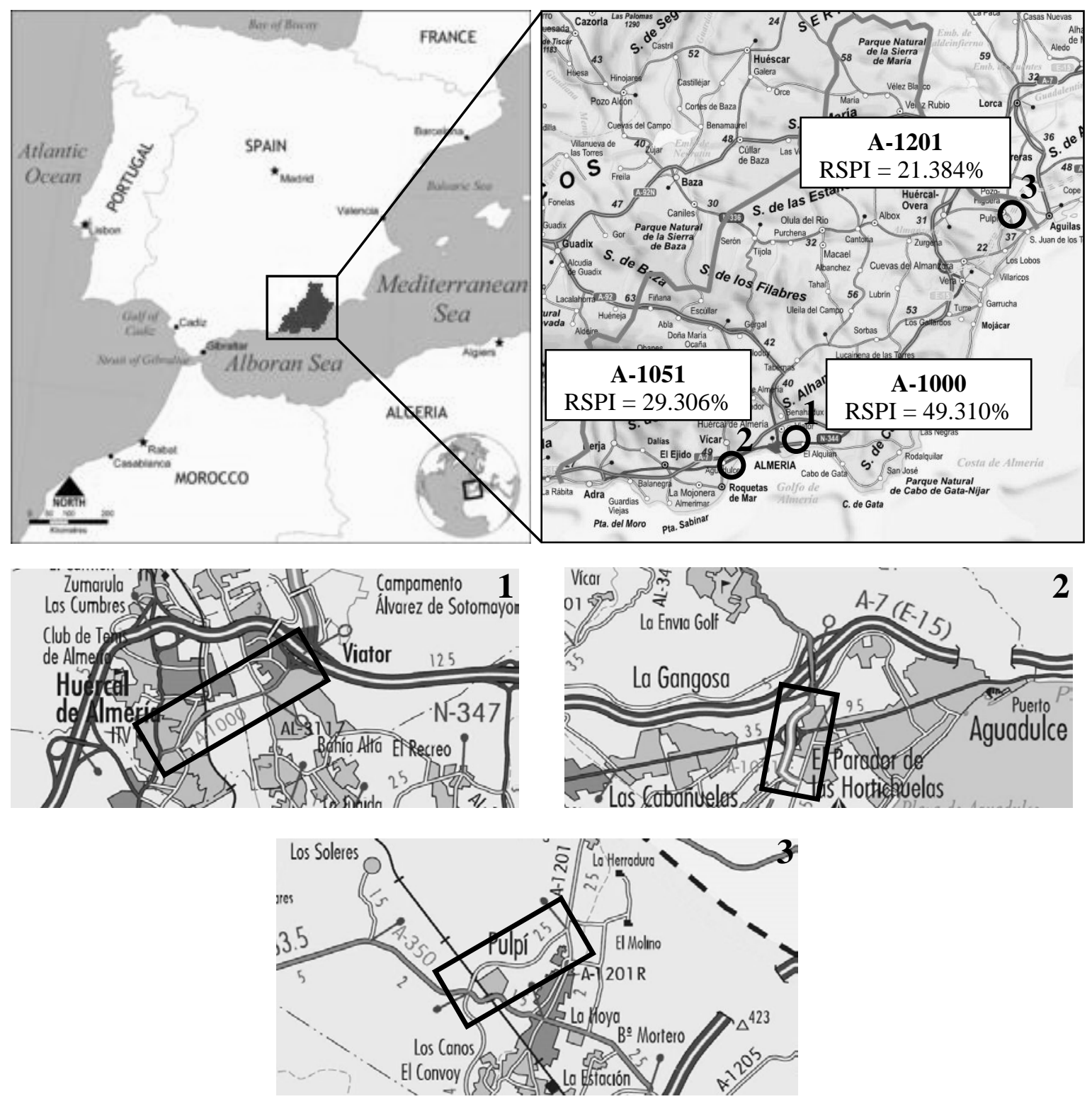